\title{
Rare inactivating PDE11A variants associated with testicular germ cell tumors
}

\author{
Anand Pathak, Douglas R Stewart, Fabio R Faucz', Paraskevi Xekouki', Sara Bass ${ }^{2}$, \\ Aurelie Vogt ${ }^{2}$, Xijun Zhang ${ }^{2}$, Joseph Boland ${ }^{2}$, Meredith Yeager ${ }^{2}$, \\ Jennifer T Loud, Katherine L Nathanson ${ }^{3}$, Katherine A McGlynn ${ }^{5}$, \\ Constantine A Stratakis', Mark H Greene and Lisa Mirabello ${ }^{4}$
}

Clinical Genetics Branch, Division of Cancer Epidemiology and Genetics, National Cancer Institute, National Institutes of Health, Bethesda, Maryland, USA

${ }^{1}$ Program on Developmental Endocrinology and Genetics, Eunice Kennedy Shriver National Institute of Child Health and Human Development, Bethesda, Maryland, USA

${ }^{2}$ Cancer Genomics Research Laboratory, Division of Cancer Epidemiology and Genetics, National Cancer Institute, $\mathrm{NIH}$, Rockville, Maryland, USA

${ }^{3}$ Perelman School of Medicine, Abramson Cancer Center, University of Pennsylvania, Philadelphia, Pennsylvania, USA

${ }^{4}$ Genetic Epidemiology Branch, and ${ }^{5}$ Hormonal and Reproductive Epidemiology Branch, Division of Cancer Epidemiology and Genetics, National Cancer Institute, National Institutes of Health, 9609 Medical Center Drive, Room 6E422, Rockville, Maryland 20850, USA

\author{
Correspondence \\ should be addressed \\ to L Mirabello \\ Email \\ mirabellol@mail.nih.gov
}

\begin{abstract}
Germline inactivating mutations of isoform 4 of phosphodiesterase (PDE) 11A (coded by the PDE11A gene) have been associated with familial adrenocortical tumors and familial testicular cancer. Testicular tissue is unique in expressing all four isoforms of PDE11A. In a prior candidate gene study of 94 familial testicular germ cell tumor (TGCT) subjects, we identified a significant association between the presence of functionally abnormal variants in PDE11A and familial TGCT risk. To validate this novel observation, we sequenced the PDE11A coding region in 259 additional TGCT patients (both familial and sporadic) and 363 controls. We identified 55 PDE11A variants: 20 missense, four splice-site, two nonsense, seven synonymous, and 22 intronic. Ten missense variants were novel; nine occurred in transcript variant 4 and one in transcript variant 3. Five rare mutations (p.F258Y, p.G291R, p.V820M, p.R545X, and p.K568R) were present only in cases and were significantly more common in cases vs controls $(P=0.0037)$. The latter two novel variants were functionally characterized and shown to be functionally inactivating, resulting in reduced PDE activity and increased CAMP levels. In further analysis of this cohort, we focused on white participants only to minimize confounding due to population stratification. This study builds upon our prior reports implicating PDE11A variants in familial TGCT, provides the first independent validation of those findings, extends that work to sporadic testicular cancer, demonstrates that these variants are uncommonly but reproducibly associated with TGCT, and refines our understanding regarding which specific inactivating PDE11A variants are most likely to be associated with TGCT risk.
\end{abstract}

\section{Key Words}

- testicular cancer

- PDE11A

- rare variants

- risk

- CAMP
Endocrine-Related Cancer (2015) 22, 909-917
(C) 2015 Society for Endocrinology Printed in Great Britain
Published by Bioscientifica Ltd 


\section{Introduction}

The molecular etiology of testicular germ cell tumors (TGCT), the most frequently occurring malignancy in young white men (ages 15-45), has yet to be fully characterized (Oosterhuis \& Looijenga 2005, Krausz \& Looijenga 2008). Several factors point to a genetic basis of TGCT. TGCT cluster in families are typically diagnosed in early adulthood and frequently present with bilateral disease (Lindor et al. 2008, Mai et al. 2009). In a study of common cancers, the estimated heritability of TGCT was $25 \%$, the third highest, suggesting a strong genetic component of risk (Czene et al. 2002). While most cancers have a familial relative risk between 1.5 and 2.5 , the relative risks for sons and brothers of men with TGCT are 4-6 and 8-10 respectively (Forman et al. 1992, Heimdal et al. 1996).

The International Testicular Cancer Linkage Consortium performed a genome-wide genetic linkage study, which suggested that the combined action of multiple common genetic variants, each with small effect sizes relative to classical, highly penetrant Mendelian traits, may explain a significant fraction of this familial aggregation (Crockford et al. 2006). Indeed, recent genome-wide association studies support the notion that many genetic loci influence TGCT risk (Nathanson et al. 2005, Kanetsky et al. 2009, Rapley et al. 2009, Turnbull et al. 2010, Kanetsky et al. 2011, Chung et al. 2013, Ruark et al. 2013, Schumacher et al. 2013, Litchfield et al. 2015). To date, 33 variants at 21 genomic regions have been significantly associated with TGCT risk. In the aggregate, they are estimated to account for 16.4 and $23.8 \%$ of the excess familial cancer risk among brothers and fathers/ sons of TGCT cases, respectively (Litchfield et al. 2015).

A candidate gene study found that germline mutations in isoform 4 of PDE11A were associated with familial/bilateral testicular cancer (Horvath et al. 2009, Azevedo et al. 2013). PDE11A is an important regulator of cyclic AMP signaling in steroidogenic tissue such as the testis, and germline mutations in this gene have been associated with familial adrenocortical tumors (Horvath et al. 2006a,b, Kelly 2014). Multiple lines of evidence suggest that PDE11A may be a good candidate TGCT risk modifier. Isoform 4 of PDE11A is expressed at high levels in testicular tissue, which is the only known tissue to express all four known isoforms of PDE11A (Horvath et al. 2006a). Furthermore, the Pde11a knockout mouse features male infertility (Wayman et al. 2005), a known TGCT risk factor (Jacobsen et al. 2000, Wayman et al. 2005, Negri et al. 2008). Interestingly, alterations in the
cAMP pathway have also been observed in non-germ cell-derived testicular tumors, such as somatic alterations in Leydig cell hyperplasia and McCune-Albright syndrome (Weinstein et al. 1991), and associated with germline alterations in PRKAR1A that underlie Carney complexassociated Sertoli cell tumors (Kirschner et al. 2000); these mutations underscore the possible importance of the cAMP pathway in testicular tissue. Studies of adrenal, prostate, and testicular cancer have suggested that PDE11A missense mutations may represent susceptibility modifiers rather than direct, sufficient causes of these tumors (Kelly 2014). Finally, the detection of increased methylation of specific $\mathrm{CpG}$ islands in the promoter region of PDE11A argues that diminished PDE11A function is a TGCT risk factor, because CpG methylation correlates with decreased mRNA expression (Kelly 2014, Mirabello et al. 2012).

In this study, we sequenced the coding regions of PDE11A in 259 new TGCT patients (168 bilateral/familial cases) and 363 male controls. Ninety-four familial TGCT cases from our previous study (Horvath et al. 2009) were also re-sequenced in the current study for comparison and to confirm our prior results. This represents a significant expansion from our previous study of PDE11A variants, which examined only cases from 64 TGCT families; in the new analysis we examine individuals from 90 families (Horvath et al. 2009). Here, we evaluated PDE11A variants in both sporadic and familial cases compared with an unrelated healthy male population. We have uncovered additional rare, deleterious $P D E 11 A$ variants that may contribute to TGCT carcinogenesis, refining the current understanding of the relationship between PDE11A and testicular cancer risk and extending our prior work to suggest that $P D E 11 A$ variants maybe involved in not only familial but also sporadic TGCT development (Horvath et al. 2009).

\section{Materials and methods}

\section{Study population}

There were 353 TGCT cases from the National Cancer Institute Clinical Genetics Branch Familial Testicular Germ Cell Study (Protocol 02-C-0178) (Horvath et al. 2009), the Servicemen's Testicular Tumor Environmental and Endocrine Determinants Study (STEED) (McGlynn et al. 2007), and the University of Pennsylvania testicular cancer study (Kanetsky et al. 2009) (Table 1). There were

Published by Bioscientifica Ltd. 
Table 1 Genotyped individuals by cohort and clinical characteristics

\begin{tabular}{l} 
Study \\
\hline Familial testicular \\
PLCO, white males \\
STEED \\
U Penn \\
Total \\
\hline
\end{tabular}

$\begin{array}{r}\hline \text { Cases } \\ \hline 180^{a} \\ 0 \\ 93 \\ 80 \\ 353 \\ \hline\end{array}$

\begin{tabular}{c}
\hline Control \\
\hline 0 \\
242 \\
121 \\
0 \\
$363^{\mathbf{b}}$ \\
\hline
\end{tabular}

ancludes 94 cases reported in Horvath et al. (2009).

${ }^{\mathrm{b}}$ None of these controls were used in the prior studies.

363 cancer-free unrelated male controls were from the prostate, lung, colorectal and ovarian (PLCO) cancer screening trial (Kramer et al. 1993) and STEED. The current analysis included 62 sporadic bilateral cases (i.e., men with bilateral TGCT and a negative TGCT family history), 200 family-history-positive (defined as families with two or more affected males) cases, and 91 sporadic cases (353 cases total). Sporadic bilateral cases and family-historypositive cases were mutually exclusive. The 94 familial case samples in this study that were previously analyzed for PDE11A mutations (Horvath et al. 2009) were excluded from the primary analysis. The study was approved by the institutional review boards of the National Cancer Institute and the University of Pennsylvania. Written informed consent was obtained from all participants.

\section{PDE11A sequencing}

Blood-derived DNA from all participants was sequenced using the Ion Torrent sequencing platform (Grand Island, NY, USA). Sample libraries were initially created using Fluidigm's (South San Francisco, CA, USA) targeted Access Array protocol. Validation of variants detected by Access Array was performed by using Ion Torrent's targeted AmpliSeq assay. All variants present on the AmpliSeq platform and common to AmpliSeq and Access Array were selected for analysis. For the Access Array library prep, targeted DNA sequencing libraries were prepared using Access Array 2-Primer PCR Amplification according to the manufacturer's protocol (Fluidigm Corporation). Postharvest, the Access Array libraries were fragmented and adapted according to the Ion Xpress Plus gDNA Fragment Library Preparation protocol (Life Technologies). Barcoded samples were pooled, templated, and sequenced on the Ion Torrent PGM Sequencer (Life Technologies), using the Ion PGM Template OT2 200 and Ion PGM Sequencing 200v2 kits, per the manufacturer's instructions.
For the Ampliseq library prep, a targeted multiplex PCR primer panel for the coding region of PDE11A was designed using the custom Ion Ampliseq Designer v2.0 (Life Technologies). The average amplicon size was $225 \mathrm{bp}$. A sample DNA of 10-20 ng was amplified using this custom Ampliseq primer pool and libraries were prepared following the manufacturer's Ion Ampliseq Library Preparation protocol (Life Technologies). Individual samples were barcoded, pooled, templated, and sequenced on the Ion Torrent PGM Sequencer, as described above. Mean read length after sequencing was $119 \mathrm{bp}$.

In total, 716 samples were sequenced; 584 samples were amplified with both the Ampliseq and Access Array platforms. Samples from 24 individuals (ten controls and 14 cases) with a high genotype missing rate were removed from the analysis. In addition, only single nucleotide polymorphisms (SNPs) with a genotyping rate of $\geq 90 \%$ were included. The genotyping rate was $96.1 \%$ for PDE11A. After data cleaning, 55 PDE11A SNPs remained in the analysis.

\section{In silico predictions}

For in silico prediction of variant deleteriousness, the combined annotation dependent depletion (CADD) score (Kircher et al. 2014) was computed (http://cadd.gs. washington.edu/).

\section{Constructs and functional studies}

For transfection experiments, the PDE11A open reading frame was cloned into the pCR3.1 plasmid, and the newly identified mutations p.(R545X) and p.(K568R) were introduced into the construct using the QuikChange Lightning Site-Directed Mutagenesis kit (Agilent, Santa Clara, CA, USA). The primers utilized in site directed mutagenesis included the following: PDE11A_K568R_F

Published by Bioscientifica Ltd. 
(GCTTGGCCCAGGACTTCCTCACTTGATC ATACATA), PDE11A_K568R_R (TATGTATGATCAAGTGAGGAAGTCCTGGGCCAAGC), PDE11A_R545X_F (GACAAAAGCCTCAAAAAGTCATTGATCTGCATCATCAAAAGGTT), and PDE11A_R545X_R (AACCTTTTGATGATGCAGATCAATGACTTTTTGAGGCTTTTGTC). The constructs were verified by sequencing. The HEK293 cell line was transiently transfected using Lipofectamine 2000 (Invitrogen) following the manufacturer's protocol. Cells were transfected with $6 \mu \mathrm{g}$ of plasmid DNA expressing either WT or the mutated form of PDE11A, then harvested $48 \mathrm{~h}$ after transfection. Mock-transfected cells, consisting of cells transfected with empty vectors only, were also utilized as experimental controls. This control was used to allow the cells to pass through the transfection process and provide data regarding any endogenous protein expression of the cells. This strategy gives a good estimate of the lower limit of phosphodiesterase (PDE) activity and the upper limit of cAMP levels. Cyclic AMP levels were determined using the cAMP [3H] Biotrak Assay System (GE Healthcare Life Science, Chalfont St Giles, UK), following the manufacturer's instructions. PDE activity was measured using BIOMOL GREENTM Reagent supplied by QuantiZyme Assay System (BIOMOL International, Plymouth Meeting, PA, USA) according to the recommended protocol. All functional studies were done in triplicate, and the average was calculated for each sample.

\section{Western blot}

Protein levels were determined by western blot using the antibodies for PDE11A, c-KIT, and KITLG (stem cell factor (SCF)/kit-ligand), using specific rabbit polyclonal antibodies (ab116556 for PDE11A, ab5506 for c-KIT, and ab52603 for KITLG; Abcam, Cambridge, MA, USA), following standard procedures (Azevedo et al. 2013).

\section{Statistical analyses}

PLINK (Purcell et al. 2007) was used to perform an allelic association test and the Fisher's exact test for each variant (http://pngu.mgh.harvard.edu/ purcell/plink/). $\chi^{2}$ analyses or $t$-tests were used to compare cases and controls for each variant by categories (missense, nonsense, and missense/nonsense) and functional analyses. Statistical analyses were performed in Excel or SAS v.9.2. Because there was prior evidence indicating that PDE11A was a strong TGCT risk candidate, supported by previous functional characterization of these variants (2009), statistical correction for multiple testing was not required.
Stratified analyses were performed in the familial affected group $(n=191)$, sporadic affected group $(n=87)$, and bilateral group $(n=61)$. The racial distribution of cases (94\% white) and controls (95\% white) was not statistically significantly different $\left(\chi^{2} P=0.94\right)$; however, we present the SNP results from white participants only to minimize confounding due to population structure.

\section{Results}

We identified 55 PDE11A variants in all 716 subjects: 20 missense variants, four splice variants, two nonsense variants, seven synonymous changes, and 22 intronic variants. We confirmed ten missense variants, two splice sites, and one nonsense mutation previously reported by Horvath et al. (2009). In the 94 samples from the Horvath et al. study that were re-sequenced in the present investigation, our sequencing results were identical with previous findings. Additionally, we detected several novel variants in the new samples: nine missense, two splice site, and one nonsense variant. Nine of the novel missense variants were in PDE11A isoform 4, and one was in isoform 3.

Several rare PDE11A variants were found only in the TGCT cases (Table 2). We separated the samples previously studied (Horvath et al. 2009) from those in the current validation study. We did not observe the previously reported F258Y or G291R variants in our validation study; of note, these variants have not been observed in the Exome Aggregation Consortium (ExaC) database (Table 2) or in controls from our previous study (Horvath et al. 2009). We did find another case with a V820M mutation. V820M has a CADD score (Kircher et al. 2014) of 25.8 , placing it in the top $1 \%$ of predicted deleterious variants. In addition, we detected a novel missense variant, K568R (CADD score $=19.8$ ), and novel nonsense variant, R545X (CADD score=23.2), that were only present in TGCT cases: K568R was in a white familial seminoma case and R545X was in an African-American sporadic seminoma case (ExaC minor allele frequency (MAF) African: 0.0097\%). Of note, in 1000 genomes this variant was only seen in the African-Caribbean group $(\mathrm{MAF}=0.552 \%)$. In our validation study as a group, there were three missense/nonsense variants observed in 252 cases vs zero in the 353 controls $(P=0.04)$. Combining the cases in our current validation study with the cases from Horvath et al. (2009), there were five missense/nonsense variants observed in eight cases that were absent from all controls $(P=0.0037)$. The racial distribution of individuals with these rare variants is listed in Supplementary Table 1,

Published by Bioscientifica Ltd. 


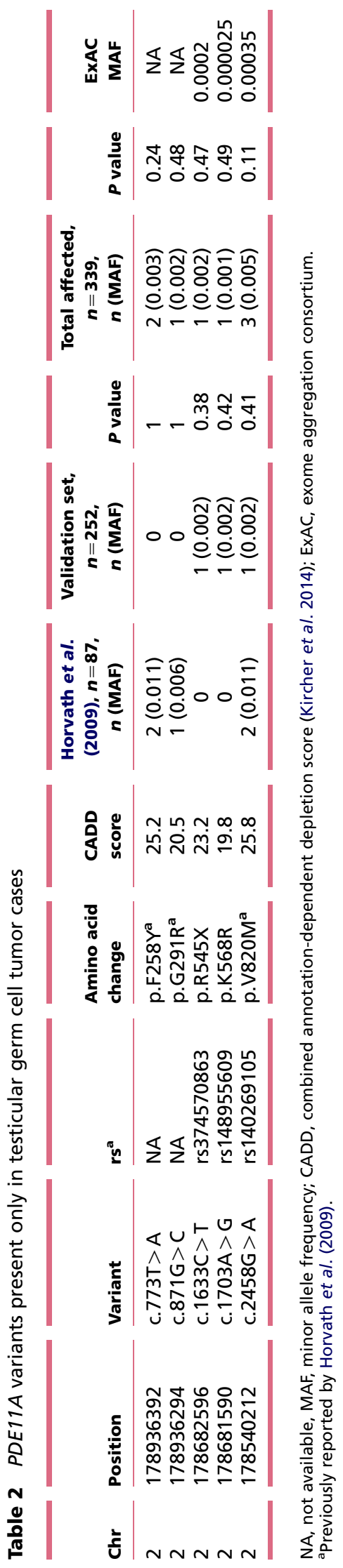

http://erc.endocrinology-journals.org DOI: 10.1530/ERC-15-0034
(C) 2015 Society for Endocrinology Printed in Great Britain see section on supplementary data given at the end of this article.

There were four intronic variants that only occurred in TGCT cases (Supplementary Table 2, see section on supplementary data given at the end of this article). The frequency of the intronic variant at Chr2:178634135 (NM_016953.3: c.1738-34G > T) was significantly increased in the validation TGCT cases (MAF $=1.0 \%, P=0.01$ ), particularly among the sporadic cases $(\mathrm{MAF}=1.7 \%$, $P=0.008$ ); it was not detected in controls or in Horvath et al. (2009). None of the other intronic variants differed significantly between cases and controls.

Table 3 lists the variants observed in white participants significantly associated with specific case subgroups in the stratified analyses, excluding the case samples in Horvath et al. (2009). We observed a statistically significant excess for an intronic variant (chr2:178681500; NM_016953.3:c.1737+56A $>$ T) in sporadic testicular cancer cases $(\mathrm{MAF}=10.0 \%)$ vs unaffected controls $(\mathrm{MAF}=2.7 \% ; P=0.0003)$; this variant was not commonly observed in either the familial $(\mathrm{MAF}=1.5 \%)$ or bilateral cases $(\mathrm{MAF}=0 \%)$. A splice site variant (chr2:178769917; NM_016953.3:c.1072-3C > T) had a significantly reduced frequency in sporadic cases only $(\mathrm{MAF}=8.3 \%)$ compared with controls $(\mathrm{MAF}=14.8 \% ; P=0.04)$. This splice site variant was previously reported to be significantly increased among familial and bilateral TGCT cases $(\mathrm{MAF}=19 \%)$ relative to endocrine-negative controls $(\mathrm{MAF}=9.9 \%)$ (Horvath et al. 2009); here we find a suggestion of an increase in the bilateral cases, but there were no significant differences between our familial (13.9\%; $P=0.82)$ or bilateral $(22.7 \% ; P=0.06)$ cases and controls. We also found an intronic variant (chr2: $178528703)$ with an increased frequency in our familial cases $(21.3 \%)$ vs controls $(15.1 \%, P=0.04)$.

There were six PDE11A variants (R184Q, Q279E, N298, I552T, S570P, and Y644C) uncovered by our sequencing that were not significantly different between white cases and controls (Supplementary Table 3, see section on supplementary data given at the end of this article). Eight additional nonsignificant variants were identified and previously reported (R52T, A349T, R307X, D609N, Y727C, R804H, R867G, and R878V) (Horvath et al. 2009) (Supplementary Table 3).

\section{PDE11A mutation functional characterization}

We used cell line studies to characterize the cAMP levels and PDE activity of the two new variants (p.K568R and p.R545X) identified in this study. Transfection

Published by Bioscientifica Ltd. 


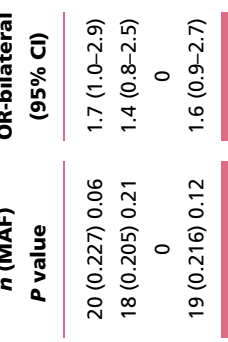

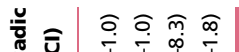

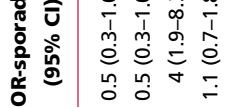

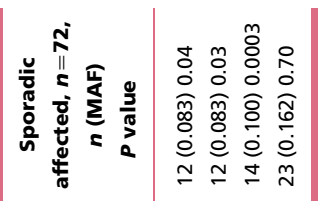

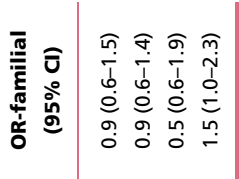

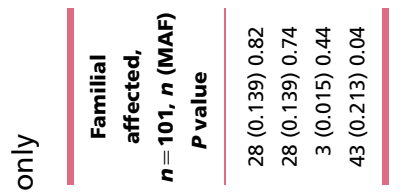

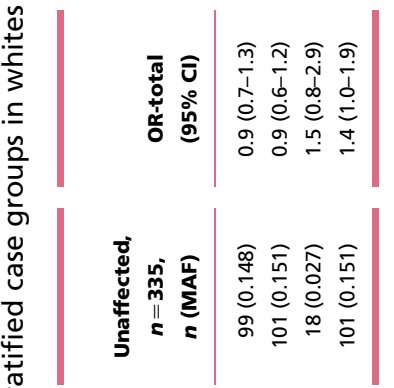

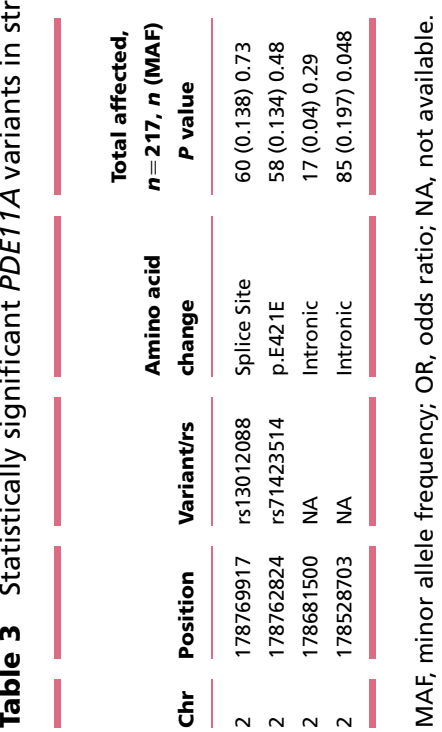

http://erc.endocrinology-journals.org DOI: 10.1530/ERC-15-0034

(C) 2015 Society for Endocrinology Printed in Great Britain experiments were performed using HEK293 cell lines and expression vectors harboring the p.R545X and p.K568R variants. We detected higher cAMP levels in the cell lines for each PDE11A mutation relative to WT, suggesting a reduced ability of these mutant PDE11A proteins to degrade cAMP (Fig. 1A). Post-transfection changes in PDE activity were negatively correlated with cAMP levels: PDE activity was lower vs WT PDE11A-transfected HEK293 cells for both mutation-bearing constructs (Fig. 1B).

A western blot showed lower PDE11A levels in the p.K568R HEK293 lysate cell line compared with WT (Fig. 2A). In the p.R545X HEK293 lysate cell line the expected $100 \mathrm{kDa}$ band for PDE11A was not detected; instead, we observed a smaller band $(\sim 60 \mathrm{kDa})$, indicating a smaller protein product as a result of this premature stop codon (Fig. 2A). No difference was seen for c-Kit and KITLG levels by immunoblot in p.K568R- and p.R545Xtransfected cell lines compared with the WT PDE11A transfected cell line (Fig. 2B).

\section{Discussion}

In our combined studies, we have identified five rare missense and nonsense PDE11A variants that present only in TGCT cases: p.F258Y, p.G291R, p.V820M, p.R545X, and p.K568R. The two variants detected in our replication cohort, p.R545X and p.K568R, had not been previously reported. These variants were absent from all 353 genotyped controls and had scaled $C$-scores from the bioinformatic CADD algorithm in the top $1 \%$ of deleteriousness, suggesting that they are likely to be associated with TGCT and may play a role in pathogenesis. Furthermore, we have shown that the two newly detected mutations in our current case series, K568R and R545X, resulted in reduced PDE activity and increased cAMP levels using cell lines. The other three rare variants (p.F258Y, p.G291R, and p.V820M), observed only in the TGCT cases, had been shown previously to be functionally inactivating mutations (Horvath et al. 2009).

Our findings confirm that the two missense changes detected in our prior study but not in this one, F258Y and G291R, were only observed in TGCT cases; furthermore, they were absent from our 353 controls, as was the case in our prior report (Horvath et al. 2009). These were the only two mutations in the previous study to show a significant prevalence difference relative to all three of their control groups $(n=1032)$ : the endocrine-negative controls, the Coriell controls, and the New York Cancer Project controls. Our results further confirm the V820M variant previously associated with testicular cancer (Horvath et al. 2009), as it

Published by Bioscientifica Ltd 

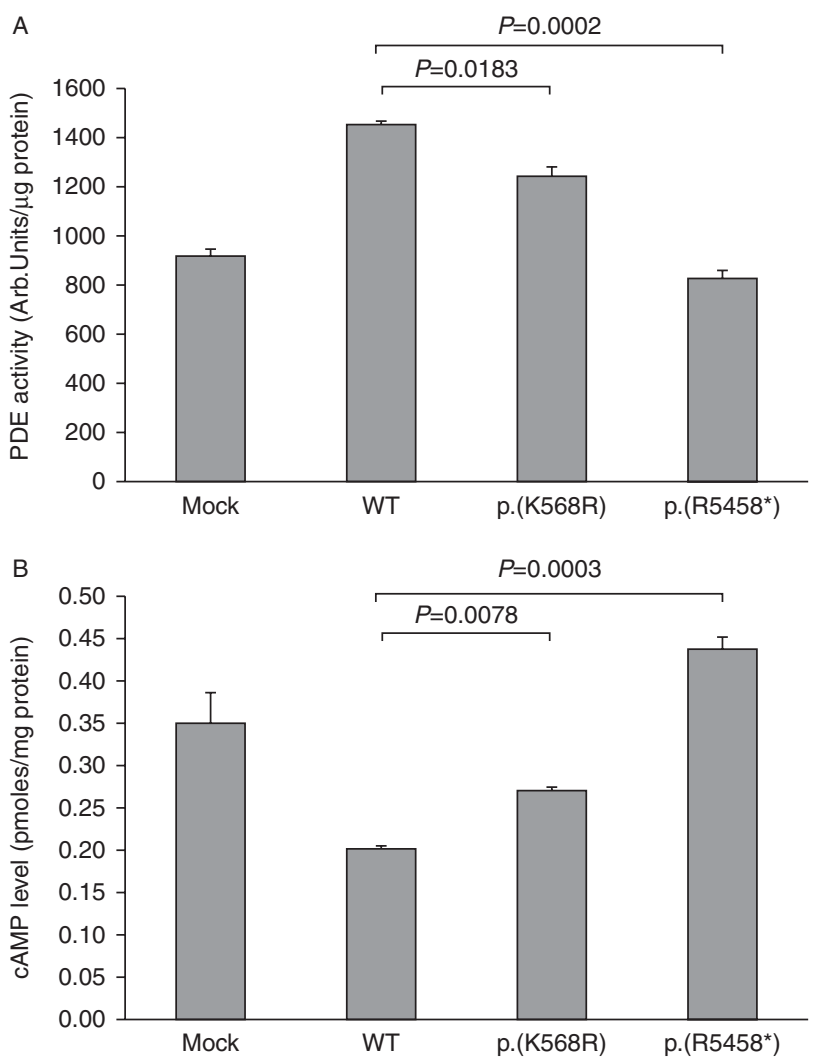

Figure 1

Phosphodiesterase (PDE) activity (A) and CAMP levels (B) after transfection of HEK293 cells with empty (Mock), WT, and mutant PDE11A expression vectors. Mock-transfected cells, consisting of cells transfected with empty vectors only, were utilized as experimental controls, $t$-tests were used for these comparisons. ${ }^{*}, P<0.05$.

was observed in one additional case in our study but not in our controls. However, we did not find an overall higher frequency of PDE11A coding variants (all missense and nonsense variants combined) in cases vs controls, as had been reported by Horvath et al. In our study, the frequency of coding variants in both cases and controls was quite high (15.9 and $15.6 \%$ respectively), confirming that PDE11A is a highly variable gene (Kelly 2014). These inter-study inconsistencies may be due to control group characteristics, which differed significantly between this and the prior report. In the latter study, the variants as a group (missense and nonsense) were significantly more common in TGCT cases vs only the endocrine-negative control group, which consisted of volunteers of mostly European descent who had been screened clinically and biochemically and found to have no endocrine disorders (Horvath et al. 2009). The frequency of nonsense and missense mutations in that control group was only $3 \%$, which is much lower than the $15 \%$ frequency of these variants observed in our unselected control group. The endocrine-negative control group may have been an 'extreme normal' population, with lower variant rates than one would encounter in an unselected population. Our current control group is likely to be more representative of the general population.

We did not detect a significant change in expression of KITLG in relation to our newly identified PDE11A mutations, p.R545X and p.K568R. Our previous study had shown that the other rare PDE11A mutations - p.F258Y, p.G291R, and p.V820M - resulted in an increased expression of KITLG (Azevedo et al. 2013). In our current experiments, we used HEK293 cells, whereas the previous experiments were conducted also in testicular embryonic cancer (NTERA-2) cells and the seminoma cell line TCAM-2 (Azevedo et al. 2013). Thus, we cannot exclude the possibility that expression of PDE11A p.R545X and p.K568R mutants may also be associated with the modulation of the KITLG signaling in testicular cancer cells.

While the current analysis examined the relationship between PDE11A variation and testicular cancer in nearly twice the number of bilateral/familial cases as our first

A

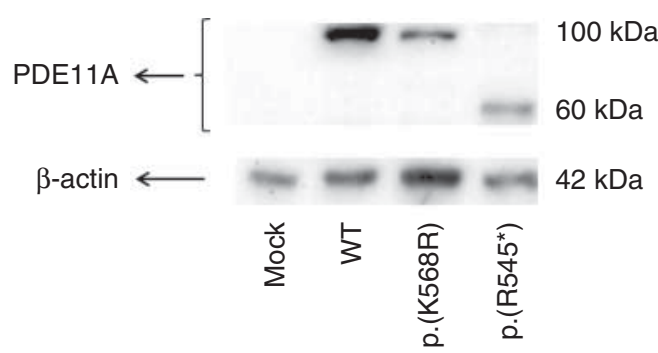

B

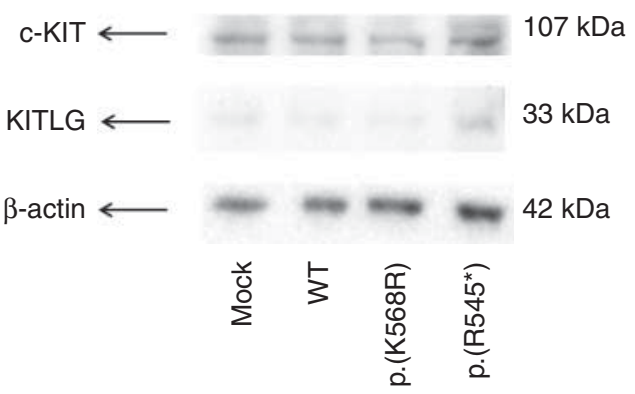

Figure 2

Western blot analysis of protein lysate from HEK 293 cell line transfected with WT and mutant PDE11A expression vectors, stained with (A) PDE11A antibody and (B) C-Kit (CKIT) and SCF (KITLG) antibodies. Mock-transfected cells, consisting of cells transfected with empty vectors only, were utilized as experimental controls. *, $P<0.05$.

Published by Bioscientifica Ltd. 
study, and for the first time in a cohort of sporadic TGCT cases, there are several limitations of this study. First, subjects of all races were included originally, which resulted in the identification of a truncating mutation in an African-American subject. However, to limit the effect of population stratification, we limited our final analysis to white participants only. Another limitation of this study was that we performed our transfection experiments in HEK293 cell lines rather than the TCAM-2 and NTERA- 2 cell lines previously used. Therefore, we cannot exclude the possibility that the absence of changes in KITLG expression in the HEK293 cell lines was not a cell line specific effect. Thus, investigating the effect of our novel mutations on KITLG expression is an attractive candidate for future studies using a broader range of cell lines. Finally, it is possible that PDE11A haplotypes (i.e., variants in cis with those we identified) (Jordan et al. 2015) might have an influence on susceptibility to testicular cancer; given the high frequency of common SNPs in PDE11A, this is a possibility. Future studies should examine the effect of PDE11A haplotypes on susceptibility to testicular cancer.

In summary, this study refines our understanding of which specific variants in PDE11A are most likely to be disease associated. We determined that although not all exonic PDE11A variants (as a group) are associated with TGCT risk, it appears that a select subset of rare missense and nonsense variants are associated with risk. These variants do not aggregate in the same region of the gene. These variants were shown to be functionally inactivating and may have a role in TGCT pathogenesis ultimately through increased cAMP levels. It is possible that the effect of PDE11A sequence variants in such a highly polymorphic gene is amplified or mitigated by the presence of other variants that are present in cis in the sequence (Jordan et al. 2015); we did not study this effect here. We have extended our earlier work (conducted specifically in familial TGCT) to the broader context of sporadic TGCT, documenting that inactivating PDE11A variants occur in both TGCT subsets. These data suggest that certain inactivating PDE11A variants are significantly associated with TGCT risk and provide further support for the hypothesis that inactivating variants in PDE11A are uncommonly, but reproducibly, associated with TGCT risk. This further supports the general view that familial and sporadic TGCT are clinically, epidemiologically, and genetically similar (Greene et al. 2015). Further careful examination of these specific PDE11A variants in relation to TGCT etiology is warranted.

\section{Supplementary data}

This is linked to the online version of the paper at http://dx.doi.org/10.1530/ ERC-15-0034.

\section{Declaration of interest}

The authors have no conflict of interest that could be perceived as prejudicing the impartiality of the research reported.

\section{Funding}

This project has been funded in part with funds from the National Cancer Institute, National Institutes of Health. This work was supported by the Division of Cancer Epidemiology and Genetics of the Intramural Research Program of the National Cancer Institute (A Pathak, D R Stewart, S Bass, A Vogt, M Yeager, J T Loud, K A McGlynn, M H Greene, and L Mirabello) and the Intramural Research Program of the Eunice Kennedy Shriver National Institute of Child Health and Human Development of the National Institute of Health (F R Faucz, P Xekouki, C A Stratakis).

\section{Author contribution statement}

A Pathak analyzed the data set and wrote the manuscript. M H Greene designed the study and contributed to the analysis and manuscript preparation. D R Stewart supervised the project and edited the manuscript. F R Faucz and P Xekouki performed laboratory studies. S Bass, X Zhang, $J$ Boland, and $\mathrm{M}$ Yeager generated the sequencing data and performed initial bioinformatic analyses. J T Loud provided the familial samples and reviewed the manuscript. $K \mathrm{~L}$ Nathanson provided the University of Pennsylvania samples and reviewed the manuscript. K A McGlynn provided the STEED samples and reviewed the manuscript. C A Stratakis and M H Greene edited the manuscript. L Mirabello directed and supervised the data analysis and edited the manuscript.

\section{Acknowledgements}

The content of this publication does not necessarily reflect the views or policies of the Department of Health and Human Services, nor does mention of trade names, commercial products, or organizations imply endorsement by the U.S. Government. We thank Dr Maria Nesterova (formerly of NICHD, NIH) for assisting with the transfections and the protein kinase $A$ assays of the described experiments.

\section{References}

Azevedo MF, Horvath A, Bornstein ER, Almeida MQ, Xekouki P, Faucz FR, Gourgari E, Nadella K, Remmers EF, Quezado M et al. 2013 Cyclic AMP and c-KIT signaling in familial testicular germ cell tumor predisposition. Journal of Clinical Endocrinology and Metabolism 98 E1393-E1400. (doi:10.1210/jc.2012-2838)

Chung CC, Kanetsky PA, Wang Z, Hildebrandt MA, Koster R, Skotheim RI, Kratz CP, Turnbull C, Cortessis VK, Bakken AC et al. 2013 Meta-analysis identifies four new loci associated with testicular germ cell tumor. Nature Genetics 45 680-685. (doi:10.1038/ng.2634)

Crockford GP, Linger R, Hockley S, Dudakia D, Johnson L, Huddart R, Tucker K, Friedlander M, Phillips KA, Hogg D et al. 2006 Genome-wide linkage screen for testicular germ cell tumour susceptibility loci. Human Molecular Genetics 15 443-451. (doi:10.1093/hmg/ddi459) 
Czene K, Lichtenstein P \& Hemminki K 2002 Environmental and heritable causes of cancer among 9.6 million individuals in the Swedish Family-Cancer Database. International Journal of Cancer 99 260-266. (doi:10.1002/ijc.10332)

Forman D, Oliver RT, Brett AR, Marsh SG, Moses JH, Bodmer JG, Chilvers CE \& Pike MC 1992 Familial testicular cancer: a report of the UK family register, estimation of risk and an HLA class 1 sib-pair analysis. British Journal of Cancer 65 255-262. (doi:10.1038/bjc.1992.51)

Greene MH, Mai PL, Loud JT, Pathak A, Peters JA, Mirabello L, McMaster ML, Rosenberg P \& Stewart DR 2015 Familial testicular germ cell tumors - Overview of a multidisciplinary etiologic study. Andrology 3 47-58. (doi:10.1111/andr.294)

Heimdal K, Olsson H, Tretli S, Flodgren P, Borresen AL \& Fossa SD 1996 Familial testicular cancer in Norway and southern Sweden. British Journal of Cancer 73 964-969. (doi:10.1038/bjc.1996.173)

Horvath A, Boikos S, Giatzakis C, Robinson-White A, Groussin L, Griffin KJ, Stein E, Levine E, Delimpasi G, Hsiao HP et al. 2006a A genome-wide scan identifies mutations in the gene encoding phosphodiesterase 11A4 (PDE11A) in individuals with adrenocortical hyperplasia. Nature Genetics 38 794-800. (doi:10.1038/ng1809)

Horvath A, Giatzakis C, Robinson-White A, Boikos S, Levine E, Griffin K, Stein E, Kamvissi V, Soni P, Bossis I et al. 2006b Adrenal hyperplasia and adenomas are associated with inhibition of phosphodiesterase $11 \mathrm{~A}$ in carriers of PDE11A sequence variants that are frequent in the population. Cancer Research 66 11571-11575. (doi:10.1158/0008-5472. CAN-06-2914)

Horvath A, Korde L, Greene MH, Libe R, Osorio P, Faucz FR, Raffin-Sanson ML, Tsang KM, Drori-Herishanu L, Patronas Y et al. 2009 Functional phosphodiesterase 11A mutations may modify the risk of familial and bilateral testicular germ cell tumors. Cancer Research 69 5301-5306. (doi:10.1158/0008-5472.CAN-09-0884)

Jacobsen R, Bostofte E, Engholm G, Hansen J, Olsen JH, Skakkebaek NE \& Moller H 2000 Risk of testicular cancer in men with abnormal semen characteristics: cohort study. British Medical Journal 321 789-792. (doi:10.1136/bmj.321.7264.789)

Jordan DM, Frangakis SG, Golzio C, Cassa CA, Kurtzberg J, Task Force for Neonatal Genomics X, Davis EE, Sunyaev SR \& Katsanis N 2015 Identification of cis-suppression of human disease mutations by comparative genomics. Nature $\mathbf{5 2 4} 225-229$. (doi:10.1038/ nature14497)

Kanetsky PA, Mitra N, Vardhanabhuti S, Li M, Vaughn DJ, Letrero R, Ciosek SL, Doody DR, Smith LM, Weaver J et al. 2009 Common variation in KITLG and at 5q31.3 predisposes to testicular germ cell cancer. Nature Genetics 41 811-815. (doi:10.1038/ng.393)

Kanetsky PA, Mitra N, Vardhanabhuti S, Vaughn DJ, Li M, Ciosek SL, Letrero R, D'Andrea K, Vaddi M, Doody DR et al. 2011 A second independent locus within DMRT1 is associated with testicular germ cell tumor susceptibility. Human Molecular Genetics 20 3109-3117. (doi:10.1093/hmg/ddr207)

Kelly MP 2014 Does phosphodiesterase 11A (PDE11A) hold promise as a future therapeutic target? Current Pharmaceutical Design 21 389-416. (doi:10.2174/1381612820666140826114941)

Kircher M, Witten DM, Jain P, O'Roak BJ, Cooper GM \& Shendure J 2014 A general framework for estimating the relative pathogenicity of human genetic variants. Nature Genetics 46 310-315. (doi:10.1038/ng.2892)

Kirschner LS, Carney JA, Pack SD, Taymans SE, Giatzakis C, Cho YS, Cho-Chung YS \& Stratakis CA 2000 Mutations of the gene encoding the protein kinase A type I-alpha regulatory subunit in patients with the Carney complex. Nature Genetics 26 89-92. (doi:10.1038/79238)

Kramer BS, Gohagan J, Prorok PC \& Smart C 1993 A National Cancer Institute sponsored screening trial for prostatic, lung, colorectal, and ovarian cancers. Cancer 71 589-593. (doi:10.1002/cncr.2820710215)
Krausz C \& Looijenga LHJ 2008 Genetic aspects of testicular germ cell tumors. Cell Cycle 7 3519-3524. (doi:10.4161/cc.7.22.6980)

Lindor NM, McMaster ML, Lindor CJ \& Greene MH 2008 Concise handbook of familial cancer susceptibility syndromes - second edition. Journal of the National Cancer Institute. Monographs 38 1-93. (doi:10.1093/jncimonographs/lgn001)

Litchfield K, Sultana R, Renwick A, Dudakia D, Seal S, Ramsay E, Powell S, Elliott A, Warren-Perry M, Eeles R et al. 2015 Multi-stage genome-wide association study identifies new susceptibility locus for testicular germ cell tumour on chromosome 3q25. Human Molecular Genetics 24 1169-1176. (doi:10.1093/hmg/ddu511)

Mai PL, Chen BE, Tucker K, Friedlander M, Phillips K-A, Hogg D, Jewett MAS, Bodrogi I, Geczi L, Olah E et al. 2009 Younger age-at-diagnosis for familial malignant testicular germ cell tumor. Familial Cancer 8 451-456. (doi:10.1007/s10689-009-9264-6)

McGlynn KA, Sakoda LC, Rubertone MV, Sesterhenn IA, Lyu C, Graubard BI \& Erickson RL 2007 Body size, dairy consumption, puberty, and risk of testicular germ cell tumors. American Journal of Epidemiology 165 355-363. (doi:10.1093/aje/kwk019)

Mirabello L, Kratz CP, Savage SA \& Greene MH 2012 Promoter methylation of candidate genes associated with familial testicular cancer. International Journal of Molecular Epidemiology and Genetics 3 213-227.

Nathanson KL, Kanetsky PA, Hawes R, Vaughn DJ, Letrero R, Tucker K, Friedlander M, Phillips KA, Hogg D, Jewett MA et al. 2005 The Y deletion $\mathrm{gr} / \mathrm{gr}$ and susceptibility to testicular germ cell tumor. American Journal of Human Genetics 77 1034-1043. (doi:10.1086/498455)

Negri L, Benaglia R, Fiamengo B, Pizzocaro A, Albani E \& Levi Setti PE 2008 Cancer risk in male factor-infertility. Placenta 29 (Suppl B) 178-183. (doi:10.1016/j.placenta.2008.07.014)

Oosterhuis JW \& Looijenga LHJ 2005 Testicular germ-cell tumours in a broader perspective. Nature Reviews. Cancer 5 210-222. (doi:10.1038/ nrc1568)

Purcell S, Neale B, Todd-Brown K, Thomas L, Ferreira MA, Bender D, Maller J, Sklar P, de Bakker PI, Daly MJ et al. 2007 PLINK: a tool set for whole-genome association and population-based linkage analyses. American Journal of Human Genetics 81 559-575. (doi:10.1086/519795)

Rapley EA, Turnbull C, Al Olama AA, Dermitzakis ET, Linger R, Huddart RA, Renwick A, Hughes D, Hines S, Seal S et al. 2009 A genome-wide association study of testicular germ cell tumor. Nature Genetics $\mathbf{4 1}$ 807-810. (doi:10.1038/ng.394)

Ruark E, Seal S, McDonald H, Zhang F, Elliot A, Lau K, Perdeaux E, Rapley E, Eeles R, Peto J et al. 2013 Identification of nine new susceptibility loci for testicular cancer, including variants near DAZL and PRDM14. Nature Genetics 45 686-689. (doi:10.1038/ng.2635)

Schumacher FR, Wang Z, Skotheim RI, Koster R, Chung CC, Hildebrandt MA, Kratz CP, Bakken AC, Timothy Bishop D, Cook MB et al. 2013 Testicular germ cell tumor susceptibility associated with the UCK2 locus on chromosome 1q23. Human Molecular Genetics 22 2748-2753. (doi:10.1093/hmg/ddt109)

Turnbull C, Rapley EA, Seal S, Pernet D, Renwick A, Hughes D, Ricketts M, Linger R, Nsengimana J, Deloukas P et al. 2010 Variants near DMRT1, TERT and ATF7IP are associated with testicular germ cell cancer. Nature Genetics 42 604-607. (doi:10.1038/ng.607)

Wayman C, Phillips S, Lunny C, Webb T, Fawcett L, Baxendale R \& Burgess G 2005 Phosphodiesterase 11 (PDE11) regulation of spermatozoa physiology. International Journal of Impotence Research $\mathbf{1 7}$ 216-223. (doi:10.1038/sj.ijir.3901307)

Weinstein LS, Shenker A, Gejman PV, Merino MJ, Friedman E \& Spiegel AM 1991 Activating mutations of the stimulatory $\mathrm{G}$ protein in the McCune-Albright syndrome. New England Journal of Medicine 325 1688-1695. (doi:10.1056/NEJM199112123252403)

Received in final form 2 September 2015

Accepted 4 September 2015 http://erc.endocrinology-journals.org DOI: 10.1530/ERC-15-0034
(C) 2015 Society for Endocrinology Printed in Great Britain
Published by Bioscientifica Ltd 